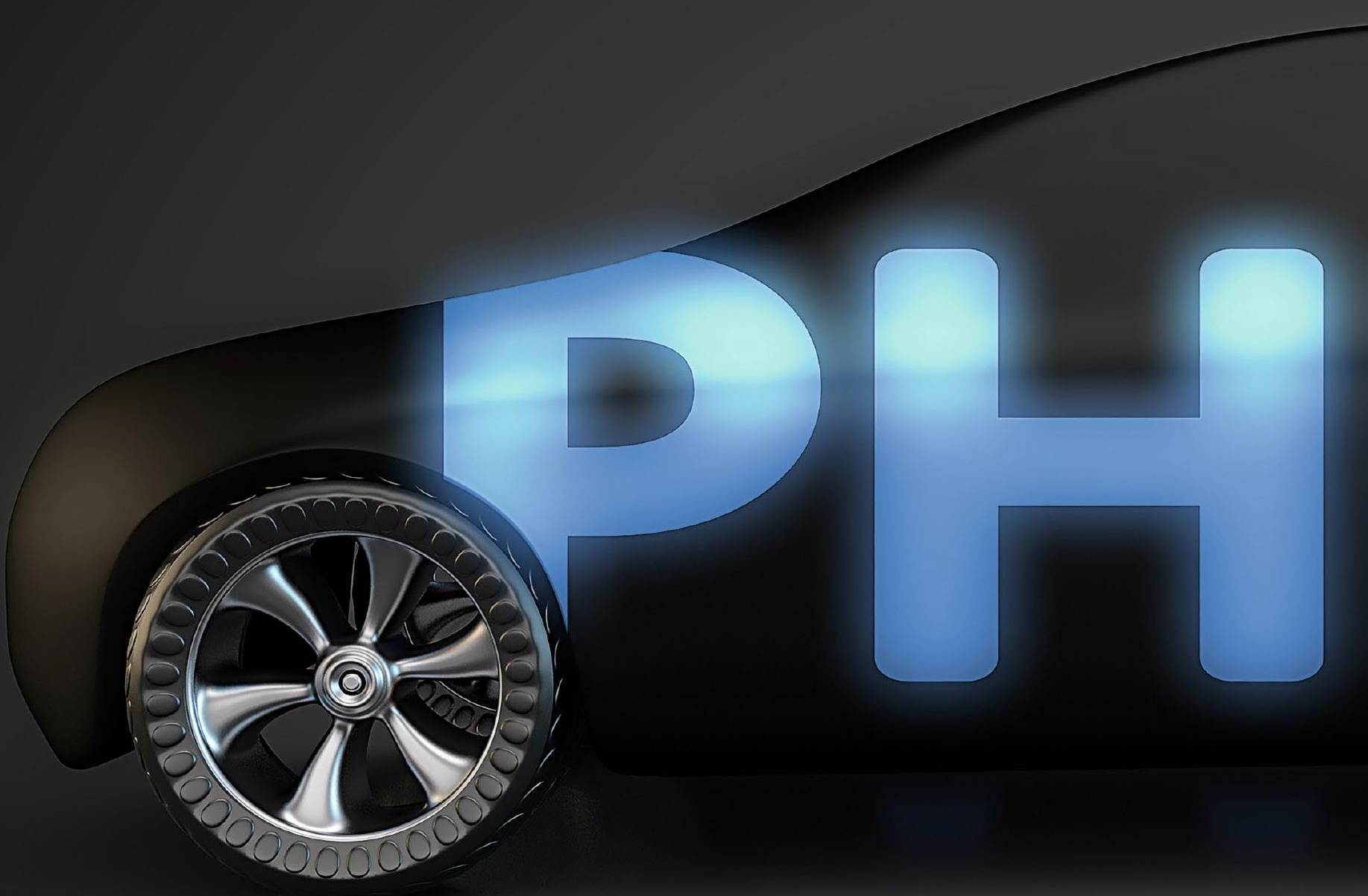

\title{
New Potential \\ for Plug-in Hybrids
}

Plug-in hybrids are often portrayed as being a con-trick with questionable environmental benefits. But their potential has not yet been fully tapped in areas such as the possibility of introducing useful incentives, the powertrain architectures and the operating strategies or even their use as a component of sector coupling. 


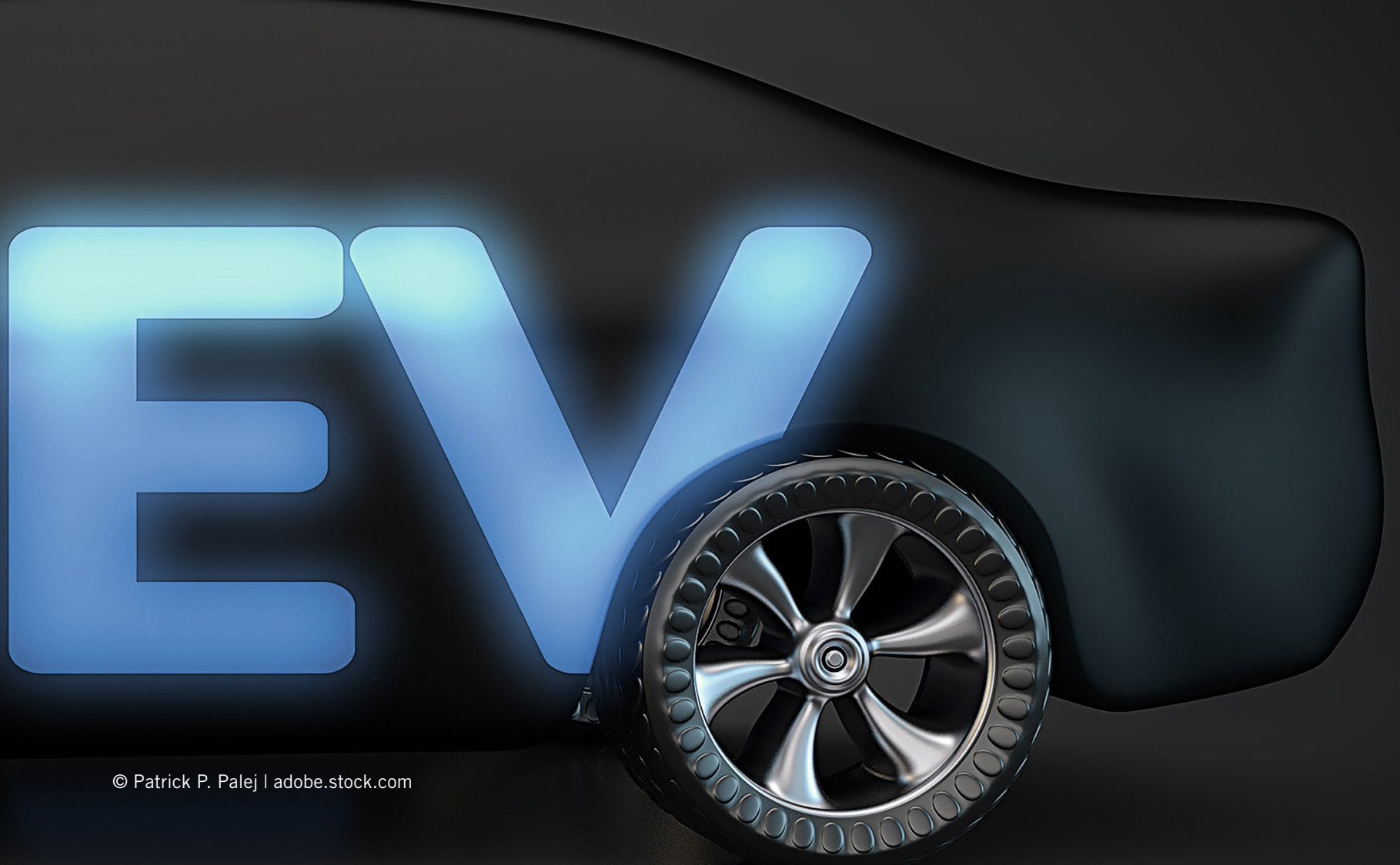

It is true that Plug-in Hybrid Electric Vehicles (PHEVs) are driven less often in electric mode than was originally intended. There are several reasons for this. For example, the German innovation bonus encourages people to take the money but not to charge the battery regularly, and the $0.5-\%$ rule relating to tax incentives for company cars functions in a similar way. During the coronavirus pandemic in particular, there have been reports of users who have had to pay for the electricity to charge their cars themselves because they were working at home and therefore preferred to use their employer's fuel card at the gas station. But what means do we have at our disposal for increasing the correct use and the acceptance of PHEVs in real life?

\section{REQUIREMENTS SPECIFICATION FOR FUTURE PHEVS}

The report published by the PHEV taskforce of Germany's National Platform Future of Mobility (NPM) makes some proposals in this area [1]. The working group was set up in mid-2020 to make "recommendations on the optimum electric efficiency of plug-in hybrid vehicles." In general terms, it is calling for "incen- tives and subsidies to be designed in such a way that there is the maximum possible amount of driving in electric mode [...]." For example, the company car tax system needs to be made more dynamic and the tax should be based on the actual electric use of the car.

As one option, the authors of the report highlight Regulation (EU) No 2018/1832, which applies to all newly type-approved vehicles from 2021 onward. The On-board Fuel Consumption Monitoring (OBFCM) that it requires allows the consumption figures for PHEVs to be recorded and stored. From a technical perspective, this provides 


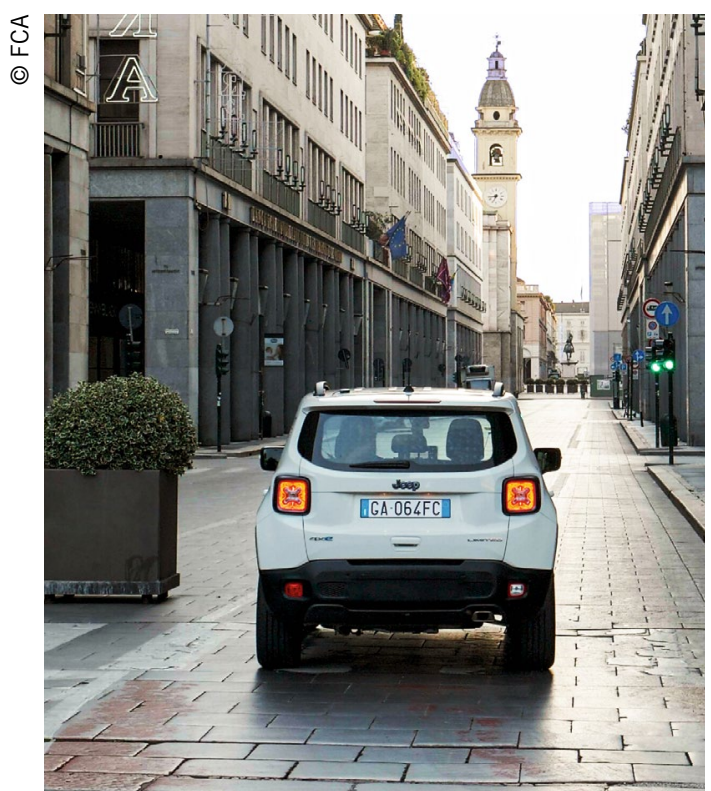

Geofencing can be deployed to ensure that PHEVs are being used as intended; this example is from FCA's Turin Geofencing Lab project

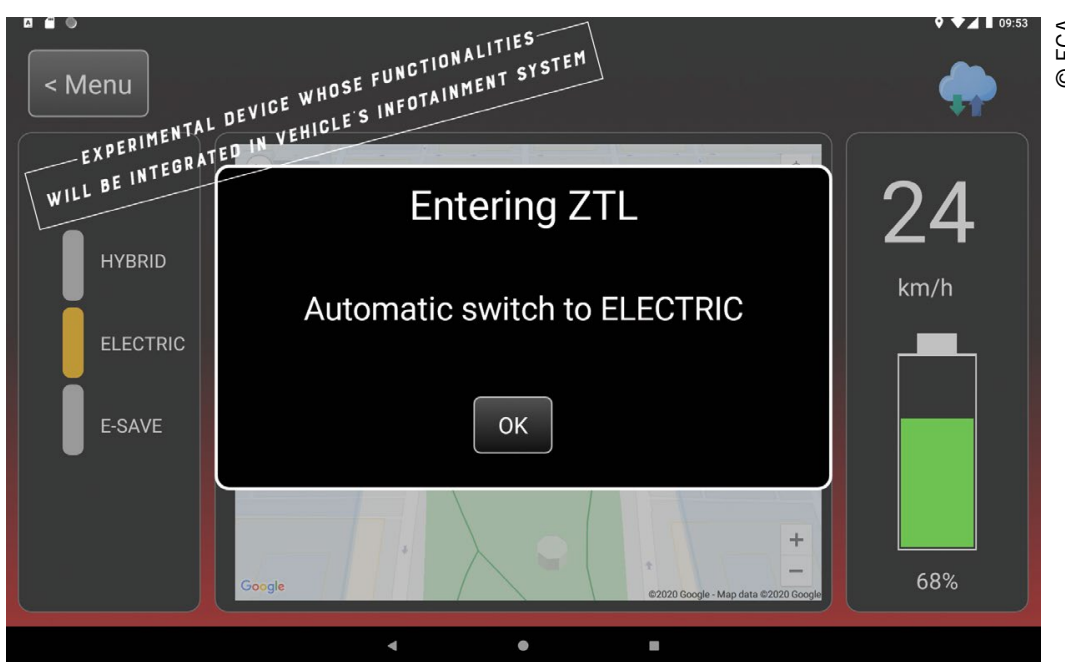

information that makes it possible to tell what proportion of the time the cars are in combustion-engine mode and in electric mode. However, from the point of view of data protection, this is problematic because there is no guarantee that the data can be transferred anonymously [2].

The NPM working group is also in favor of an electric range of 80 to $100 \mathrm{~km}$, which is a much longer distance than is currently normal. This is reflected in the plans being made by the automotive industry. For example, in early March 2021 Volkswagen announced that its next-generation PHEVs would have an electric range of up to $100 \mathrm{~km}$.

As far as recharging the battery is concerned, the taskforce believes that this will mainly be done at home and at work. The public AC charging infrastructure would therefore not necessar-

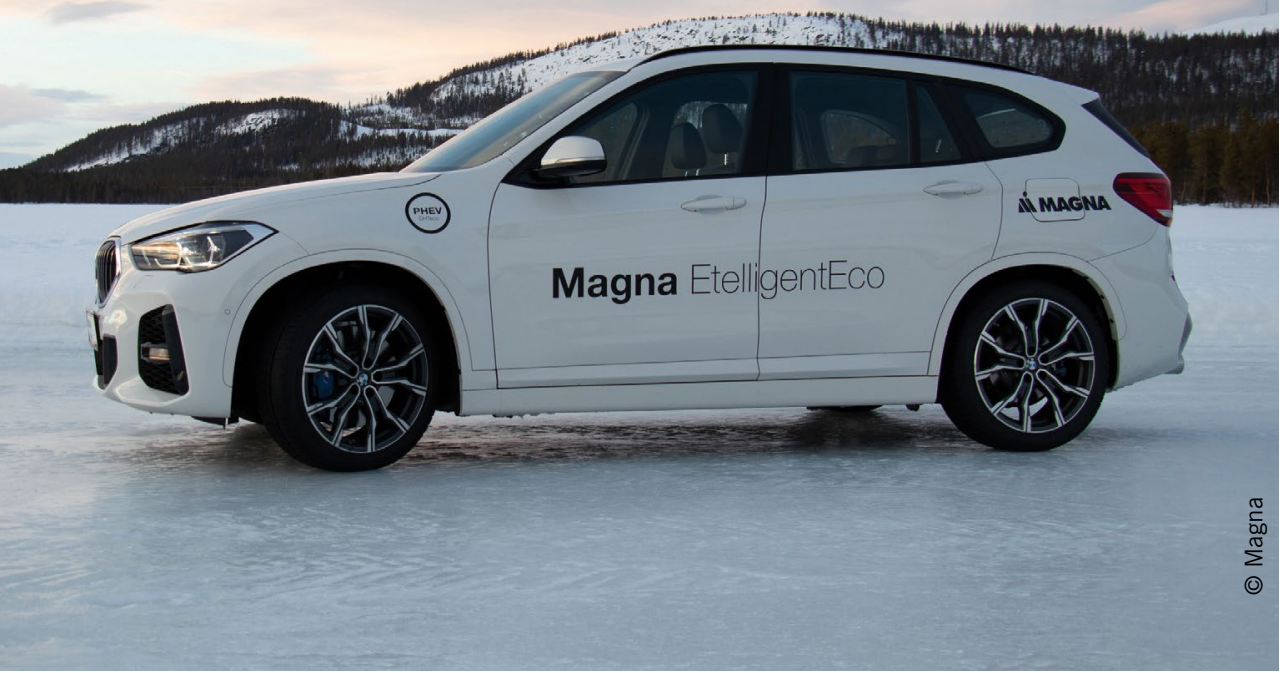

The EtelligentEco demonstrator from Magna highlights three means of making PHEVs more efficient: the performance of a dominant electric drive, a longer electric range and connected operating strategies ily need to be extended. However, the recommendation is that the charging capacity in the car should be increased to $11 \mathrm{~kW}$ and combined with three-phase charging to guarantee the symmetry of the grid. In addition, PHEVs should also be incorporated into the ecosystem in line with ISO 15118 [3].

\section{THE CONNECTED POWERTRAIN}

According to the NPM, intelligent operating strategies also offer significant potential. For example, the active route guidance system combined with an automatic analysis of driving style could suggest specific charging locations or provide electricity for zero-emission driving in inner city zones. Some of these features are already available, for example from BMW. Since 2020, the manufacturer has offered a geofencing function for its PHEVs which enables them to switch automatically to electric mode in city centers. In mid 2020, FCA launched a similar project known as the Turin Geofencing Lab [4].

Finally, the following statement in the taskforce report attracts attention: The "display of information, for example concerning fuel consumption, $\mathrm{CO}_{2}$ emissions and the charging infrastructure, either directly in the vehicle or possibly via a smartphone app, will make users' behavior transparent." The result is that smart devices could become a basic user interface for a connected operating strat- 
egy. Another benefit is that they have shorter development cycles than the powertrains and the cars. For example, new assistance functions are regularly added to Google Maps which provide help for drivers in a number of different ways. In March 2021, the company made available the option of including topographical information in route planning. In June 2021, a function will be introduced to warn drivers when they enter low-emission zones. What is currently lacking is the inclusion of vehicle data, but there is a conflict here between the need for information on $\mathrm{CO}_{2}$ emissions and the regulations concerning data protection.

Regardless of this, vehicle manufacturers and automotive industry suppliers are increasingly focusing on connected operating strategies, because they offer significant opportunities for reducing emissions. For example, during its winter testing program in Sweden this year, Magna presented its EtelligentEco demonstrator and, at the same time, highlighted the potential fuel savings offered by the connected powertrain. In its route guidance system, the car can give preference to charging stations that supply renew-

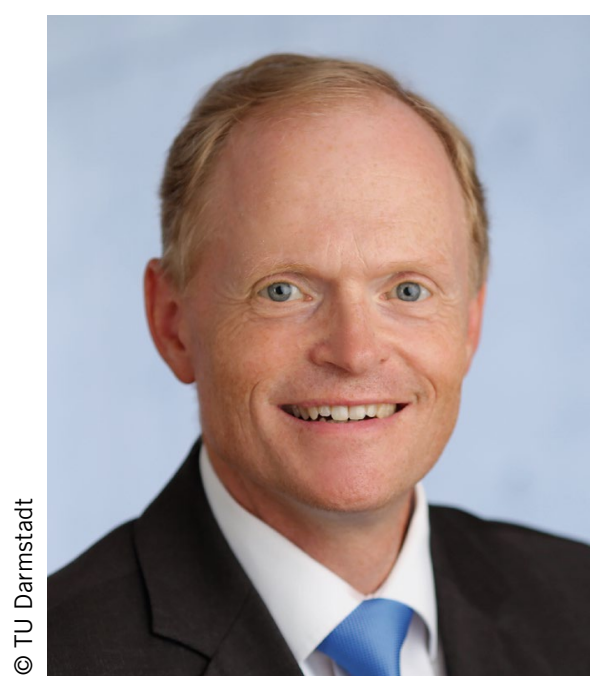

Prof. Stephan Rinderknecht Institute for Mechatronic Systems of TU Darmstadt
The DHT from AVL, which is based on an automated manual transmission, shows how much simpler in mechanical terms a dedicated hybrid transmission can be

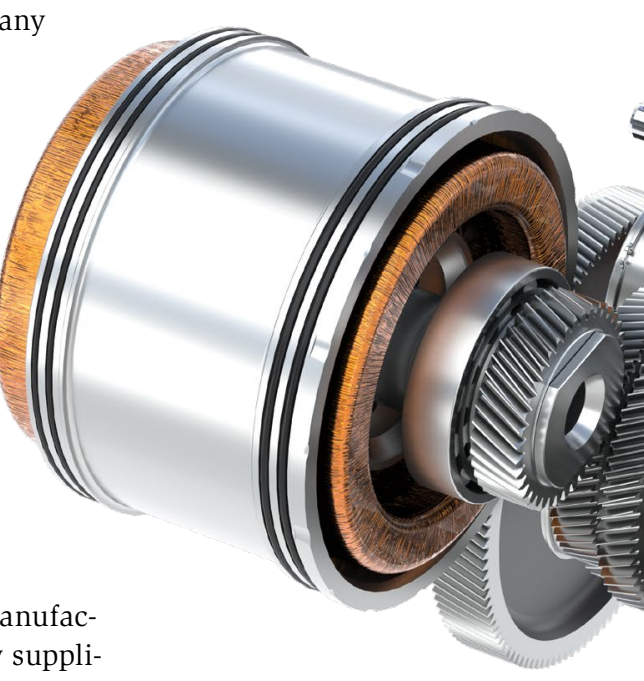

able energy in order to bring about a genuine improvement in the carbon footprint. Of course, this would require that the carbon footprint of the energy generation process is known.

Magna's demonstrator has an electric range of around $100 \mathrm{~km}$, but for this to bring benefits, driving the PHEV in electric mode must be made more attrac-

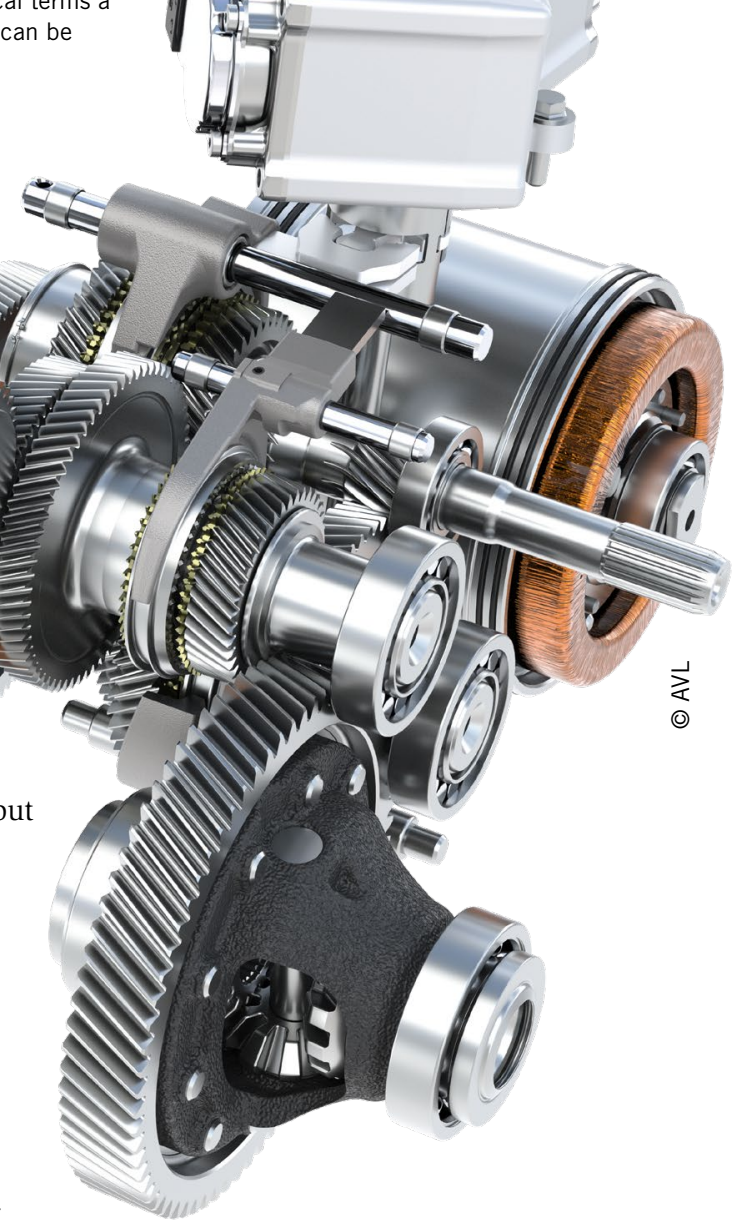

\section{2. 2 QUESTIONS FOR ...}

What do you believe is the main argument in favor of PHEVs?

RINDERKNECHT _ The focus has to be on resource efficiency for vehicles that can be used in any situation, but will only occasionally make longer journeys of over $100 \mathrm{~km}$. With a usage profile of this kind, the benefits in comparison to a fully electric vehicle that can travel longer distances include not only lighter weight, a considerable reduction in battery resources and a total range that is independent of the weather conditions, but also lower costs, the lack of the need for DC fast charging and the potential for use as a back-up power station for the grid.
How well do you think it will perform in a cradle-to-grave life cycle assessment? RINDERKNECHT _ The decisive factor for the carbon footprint is the usage profile. Our studies show that PHEVs which only make longer journeys occasionally and are mainly used in battery-electric mode have clear benefits on the basis of the current conditions for battery production and the German electricity mix. The positive features are the lighter weight of these vehicles, which brings efficiency benefits in electric mode, and the reduction in the resources needed for the battery. However, it is very important that the vehicle is used as intended and regularly charged. 


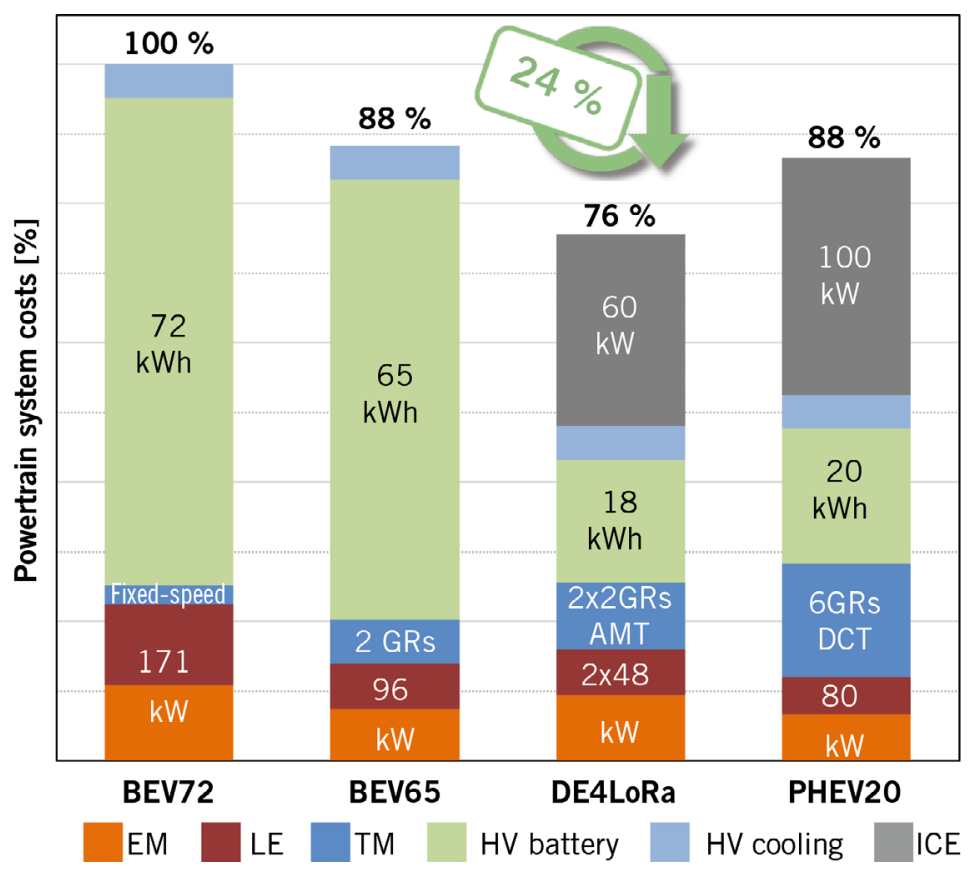

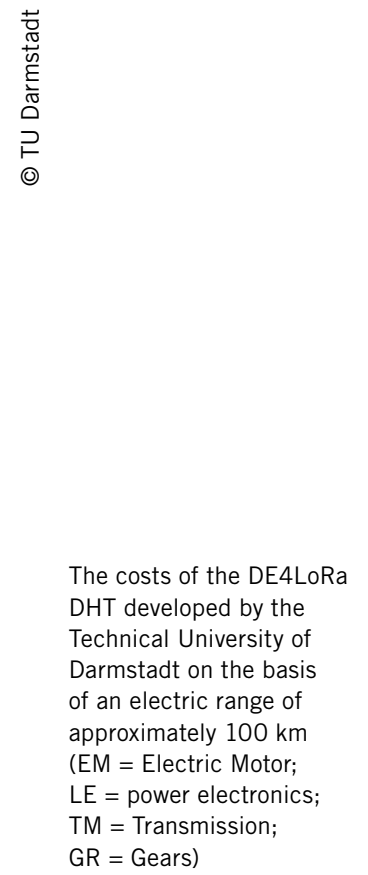

tive. The Magna car has a DHTeco Dedicated Hybrid Transmission (DHT). In principle, this is a simplified fourspeed dual-clutch transmission with an integrated $120-\mathrm{kW}$ electric motor that plays the central role and replaces the launch and reverse gears. The combustion engine is designed for a maximum input torque of $230 \mathrm{Nm}$, which is sufficient because it performs less dynamically than in current add-on hybrid drives. According to Magna, this arrangement reduces $\mathrm{CO}_{2}$ emissions and leads to a noticeable increase in terms of comfort and driving dynamics.

\section{DHTS FOR}

\section{HIGH-VOLUME SEGMENTS}

In Europe and in Asia, a whole series of DHTs is currently being developed which will offer similar features: a dominant electric drive combined with a less powerful, phlegmatized combustion engine and a simplified, cost-effective transmission design.

At the Vienna Motor Symposium, Tolga Uhlmann, Head of the Gasoline Engine division of FEV, mentioned another factor: In the future, so-called skateboard platforms will become increasingly important. These are primarily designed for all-electric applications and will therefore also redefine the package spaces for PHEVs [5]. Uhlmann believes that this will offer opportunities for the development of serial hybrids, provided that the efficiency of the combustion engines is approaching $45 \%$. Interestingly, studies carried out by FEV have shown that the real-life fuel consumption can be similar to that of serialparallel concepts, particularly in markets with speed restrictions.

Ingo Scholten from Geely also spoke at the virtual Vienna Symposium about the Chinese manufacturer's development program for dedicated drives [6], which already includes a Dedicated Hybrid Engine (DHE) with peak efficiency of $42.5 \%$. Geely's hybrid transmissions are based on a mixed serial-parallel solution with three gears for parallel operation at higher speeds. This trend for mixed architectures is also widely favored by other companies, often in combination with two electric motors.

Mario Brunner, Head of Systems Engineering, Powertrain Electrification and Transmissions at AVL, discussed this subject with the editorial team in person at their request. In the high-volume segments, he believes that there is a requirement for dedicated powertrain solutions. The key driving forces here are the costs and the need for the greatest possible efficiency. AVL has therefore developed an architecture based on a simple automated manual transmission supplemented by two electric motors. The smaller of the two motors functions as a starter or generator and can use four gears in parallel operation. The special feature of this system is that this motor can be switched to the output side to provide power in P3 mode. The second, larger electric motor operates in P3 mode only and is used primarily under heavy loads or in serial operation. The benefit of being able to use the two electric motors in different ways is that they can both operate individually or together to provide the greatest possible efficiency depending on the driving situation. For example, the smaller motor is sufficient in many situations and will function in the sweet spot under relatively heavy loads.

\section{THE RETURN OF THE RANGE EXTENDER}

Another existing solution is the DE4LoRa DHT (the name stands for "double electric drive for long range”) designed by Prof. Stephan Rinderknecht and his colleagues at the Institute for Mechatronic Systems of the Technical University of Darmstadt [7]. This four-speed transmission for parallel operation has a similar structure to a dual-clutch transmission and is equipped with an electric motor for each of its two parts, but does not need synchronizers or clutches. As with the dual-clutch transmission, gear shift- 
ing takes place in the path that is load-free. The electric motor in the other path maintains the traction. The power distribution between the two electric motors brings the additional benefit of efficient operation under partial load.

As far as the system's use is concerned, Rinderknecht describes it as a dedicated Range Extender Transmission (DRT) with a clear focus on electric mode. In hybrid operation, only a small combustion engine is needed, because it covers the basic load only and its operation is largely phlegmatized. The dynamic power is provided by the electric motors. Until now, range extenders have mainly been associated with serial hybrids. Rinderknecht's solution is also capable of serial operation, but this is only intended for special situations. The DRT is being developed further with funding from the German Federal Ministry for Economic Affairs and Energy and, at the end of the project, will be trialed in two Hyundai test vehicles [8].

Rinderknecht describes further benefits of this solution, which include the possibility of much more variable operation. For example, when the ambient temperature is very low, the driver can pull away in serial mode without first heating the traction battery to maintain its service life. One infrequent situation could also involve using the combustion engine in a non-urban setting to provide a brief power boost, which in return would make it possible to downsize the electric motors used for normal operation.

Just as interesting as the powertrain architecture is the term UHEV that Rinderknecht uses. This stands for Universal Hybrid Electric Vehicle. The UHEV will also have an electric range of $100 \mathrm{~km}$, which will cover more than $80 \%$ of average journeys. The UHEV is based on the idea of using the PHEV as a back-up generator or even as a component of sector coupling. This is not just about integrating it into a smart grid as a power storage facility. It can also perform the reverse function, because the combustion engine can be used to generate power, for example to supply the owner's house. The PHEV could step in during periods when very little solar or wind power is being generated and when critical areas such as industry and hospitals have to be given higher priority access to the available power supply.

Gernot Goppelt

\section{REFERENCES}

[1] NPM: Empfehlungen zum optimierten Nutzungsgrad von Plug-in-Hybridfahrzeugen. Online: https://www.plattform-zukunft-mobilitaet.de/2download/ empfehlungen-zum-optimierten-nutzungsgrad-von-plug-in-hybridfahrzeugen, access: April 28, 2021

[2] Deutscher Bundestag: Kleine Anfrage: Umgang mit OBFCM-Daten von Fahrzeugen. Online: https://dserver.bundestag.de/btd/19/264/1926477.pdf, access: May 5, 2021

[3] Willrett, U.: Standards for Implementing Smart Charging. In: ATZelektronik worldwide 11/2020, pp. 54-57

[4] Schäfer, P.: FCA-Konzern und Turin starten Geofencing-Projekt. Online: https://www.springerprofessional.de/link/18094932, access: May 4, 2021 [5] Uhlmann, T.: xHEV Konzept zur Erreichung der $\mathrm{CO}_{2}$-Ziele in 2030. 42. Internationales Wiener Motorensymposium, April 30, 2021

[6] Scholten, I.: Geely‘s Modulares Hybridantriebssystem. 42. Internationales Wiener Motorensymposium, April 30, 2021

[7] Rinderknecht, S.; Viehmann, A.; Schleiffer, J.-E.: Evaluation of the dedicated range-extender transmission powertrain concept DE-REX regarding efficiency, costs and complexity. Dritev - Getriebe in Fahrzeugen, Bonn, July 10, 2019 [8] BMWi: DE4LoRa - Universelles hochintegriertes 800V-Hybrid-Antriebssystem mit ganzheitlich optimierter Ökologie und Ökonomie. In: Fachprogramm: Neue Fahrzeug- und Systemtechnologien. April 28, 2021, p. 8

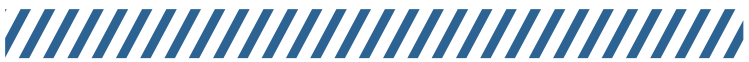 OPINION}

"A fundamental problem for evaluating PHEVs is the tank-to-wheel ssessment used by the EU. But even in this context a number of improvements are possible. These include dedicated drives which are extremely efficient in electric mode, a longer electric range and incentives that have a genuine steering effect. One important factor is the use of connectivity solutions which would allow PHEVs to interact intelligently with the infrastructure or the cloud so that their full energy-saving potential could be exploited. The possible counterarguments are that the system would be too complex and would not be ideal from the perspective of data protection. This second argument could be dismissed on the grounds that the EU wants to have access to individual fuel consumption data in any case. And what about the PHEV as an electricity generator and component of sector coupling? Plausible, but it requires a willingness to consider an energy converter such as the combustion engine as a useful system component."

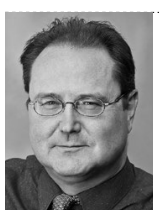

Gernot Goppelt is Freelance Journalist. 